\title{
Energetic costs of foraging in breeding Cape gannets Morus capensis
}

\author{
Ralf H. E. Mullers ${ }^{1,2, *}$, René A. Navarro ${ }^{2}$, Serge Daan ${ }^{3}$, Joost M. Tinbergen ${ }^{4}$, \\ Harro A. J. Meijer ${ }^{5}$ \\ ${ }^{1}$ Behavioural Biology Group, Center for Behavior and Neurosciences, University of Groningen, Kerklaan 30, \\ 9751 NN Haren, The Netherlands \\ ${ }^{2}$ Animal Demography Unit, Department of Zoology, University of Cape Town, Rondebosch 7701, South Africa \\ ${ }^{3}$ Faculty of Mathematics and Natural Sciences, University of Groningen, Nijenborgh 9, 9747 AG Groningen, The Netherlands \\ ${ }^{4}$ Animal Ecology Group, Centre for Ecological and Evolutionary Studies, University of Groningen, Kerklaan 30, \\ 9751 NN Haren, The Netherlands \\ ${ }^{5}$ Centre for Isotope Research, University of Groningen, Nijenborgh 4, 9747 AG Groningen, The Netherlands
}

\begin{abstract}
Seabirds fly considerable distances during the breeding season in search for food for themselves and their young. Variation in the distance from the breeding colony to the offshore food resources is expected to impact the energy spent on foraging trips. In 2005-06 and 2006-07 we studied foraging behaviour, derived time budgets during foraging trips (commuting, hunting or drifting on the sea surface) and measured the associated energy expenditure in 2 colonies of breeding Cape gannets Morus capensis. Around Ichaboe Island (Namibia) the winds were stronger and more variable than at Malgas Island (South Africa). Gannet foraging trip duration did not vary between the islands, but at Ichaboe gannets spent more time on hunting and less time drifting on the sea surface compared to Malgas birds. Gannets from Malgas made more dives during foraging trips than Ichaboe gannets (75 and 43 dives respectively). Energy expenditure during foraging trips (TEE) was estimated on average at $4203 \mathrm{~kJ} \mathrm{~d}^{-1}( \pm 693, \mathrm{n}=27)$, which was $5.5 \times$ basal metabolic rate (BMR), and did not differ between the islands. Energetic costs of foraging increased with wind speed and the fraction flying during foraging trips. The average flight costs were estimated at $85 \mathrm{~W}$, after correction for wind speed. The increased energetic cost during foraging at Malgas was associated with the large number of dives and less profitable winds: taking off after each plunge-dive would be more costly in weaker winds. The fact that TEE did not differ between the islands might suggest that Cape gannets at both islands were foraging at the boundaries of their sustainable energetic expenditure.
\end{abstract}

KEY WORDS: Energetics · Environmental conditions · Foraging behaviour · Time budgets · Trip energy expenditure

\section{INTRODUCTION}

The avian breeding season is often characterised by a high daily energy expenditure (Drent \& Daan 1980). Breeding birds have to collect enough food to sustain both their own energy requirements and those of their growing offspring. Seabirds face especially stringent energetic constraints on their foraging behaviour due to the spatial separation of breeding (land) and forag- ing (sea) areas. Food abundance is often patchy and unpredictable in pelagic habitats compared to terrestrial habitats, and seabirds have to cover long distances to obtain sufficient food (Shealer 2002). Variation in the distance from the colony to the offshore feeding sites influences the balance of energy gained and spent during foraging trips. Avian flight is one of the most expensive behaviours known (e.g. BirtFriesen et al. 1989, Ellis \& Gabrielsen 2002) and a 
major component of marine birds' energy budgets. Energy expenditure of pelagic seabirds can therefore be twice as high as those of land birds (Ellis \& Gabrielsen 2002, Tieleman \& Williams 2000).

Seabirds have evolved behavioural and morphological adaptations that minimise the energetic costs of flying. The high aspect-ratio of many seabird wings most likely evolved to take advantage of prevailing oceanic winds to soar and decrease flying costs (e.g. Schreiber \& Chovan 1986, Weimerskirch et al. 2000). For example, albatrosses conserve energy by optimising the use of wind conditions during dynamic soaring flights (Weimerskirch et al. 2000). Body morphology of albatrosses does not allow sustained flapping flight (Alerstam et al. 1993), causing them also to remain at the sea surface during periods of slack winds to conserve energy (Jouventin \& Weimerskirch 1990). Strong winds are not always advantageous: strong headwinds can significantly increase the foraging costs (Weimerskirch et al. 2000) and also stir up the sea surface, which makes it harder for seabirds to locate prey from the air (Finney et al. 1999).

While energy expenditure has been measured in several seabird species during breeding (e.g. Adams et al. 1991, Hodum \& Weathers 2003), this has rarely been done in relation to behaviour during foraging trips (Shaffer et al. 2001, Jodice et al. 2003). We equipped breeding Cape gannets Morus capensis with GPS loggers, which yielded high spatio-temporal resolution information on the movements, flight speed, total distance covered, time spent hunting, number of dives, etc. At the same time we injected these birds with doubly labelled water (DLW) and collected blood samples after the birds' return to the colony: a method to obtain estimates of daily energy expenditure (DEE). With the simultaneous application of DLW and GPS logging, we have the opportunity to assess gannet daily foraging routines in detail.

All 5 gannetries at the southern African west coast have recently declined in number of breeding pairs, which was associated with a decreased availability of anchovies Engraulis encrasicolus and sardines Sardinops sagax (Crawford et al. 2007). The reduced availability of these pelagic prey species increased the duration of foraging trips of Cape gannets (Lewis et al. 2006, Pichegru et al. 2007), and most likely, also the foraging costs. We aim to (1) investigate the energy expenditure during foraging of Cape gannets, and (2) understand how foraging behaviour and energy expenditure are associated with environmental conditions. Extending the study over 2 island colonies characterized by different population dynamics, with the colony at Malgas declining at a faster rate than at Ichaboe (Crawford et al. 2007), allows us to speculate on these population changes in relation to individual behaviour and physiology.

\section{MATERIALS AND METHODS}

Foraging behaviour and energy expenditure of Cape gannets were investigated during 2 years (2005-06 and 2006-07) at Malgas Island (South Africa, $33^{\circ} 05^{\prime} \mathrm{S}$, $\left.17^{\circ} 93^{\prime} \mathrm{E}\right)$ and in 1 year (2005-06) at Ichaboe Island (Namibia, $26^{\circ} 29^{\prime} \mathrm{S}, 14^{\circ} 94^{\prime} \mathrm{E}$ ). Due to changes in local food availability around Ichaboe in 2006-07, gannets increased their foraging trip durations (Mullers \& Tinbergen 2009) and we refrained from further disturbances to the birds for fear of causing them to desert their offspring. No data was therefore collected from Ichaboe gannets in 2006-07.

GPS logging. Cape gannets at different stages of the breeding cycle were selected to be equipped with GPS loggers (Technosmart, Rome). Gannets that left their chick and partner to commence a foraging trip were caught using a hooked pole, measured (length of the flattened wing chord to the nearest $\mathrm{mm}$ and bill to the nearest $0.1 \mathrm{~mm}$ ) and weighed (to the nearest $25 \mathrm{~g}$ ). We attached the GPS logger, sealed in 2 polyethylene bags, to their lower back and tail feathers with waterproof Tesa-tape (Beiersdorf Hamburg, Germany). The devices and the bags weighed $\sim 50 \mathrm{~g}$, i.e. approximately $2 \%$ of the adult body mass. Biometry and attaching the logger took ca. $5 \mathrm{~min}$, after which the gannet was released near the colony. The same GPS loggers had no obvious adverse effects on Cape gannet behaviour in previous studies (Grémillet et al. 2004, Lewis et al. 2006). The single chick of each focal bird was measured for bill length, wing length, and body mass ( $<1 \mathrm{~kg}$ to nearest $10 \mathrm{~g}_{i}>1 \mathrm{~kg}$ to nearest $25 \mathrm{~g}$ ) to obtain an estimate of its age. The nest was marked and monitored once per hour. When the gannet with the logger returned, it was captured, the logger retrieved, and the bird was put back on its nest. The sexes could not be distinguished in the field, so DNA isolated from collected breast feathers was used to determine their sex in retrospect (see Fridolfsson \& Ellegren 1999 for detailed methods).

Track analyses. The GPS loggers recorded geographic positions of each bird at $10 \mathrm{~s}$ intervals (ca. $10 \mathrm{~m}$ resolution). We converted the geographic coordinates of each GPS fix through the Albers' Equal Area Projection (Snyder 1982) to take the curved earth surface into account. From consecutive GPS positions of the gannets $\left(p_{t}=\right.$ position at time $t$ ) we could calculate the distance travelled $\left(D_{t}=\right.$ distance between $p_{t-1}$ and $\left.p_{t}\right)$. During actual foraging we expect gannets to be less consistent in direction than during directional flight, and to have increased path sinuosity. Sinuosity at time $t$ was defined as the ratio between the distance flown (DF) along the GPS path and the straight line displacement (Di) between the start and end of the sinuosity window $(t \pm 2)$. So: 


$$
\begin{aligned}
& \mathrm{DF}_{t}=\Sigma \sqrt{ }\left[\left(x_{t-1}-x_{t}\right)^{2}+\left(y_{t-1}-y_{t}\right)^{2}\right] \\
& \text { for } \mathrm{t}=-1 \text { to } \mathrm{t}=2 \text {, and: } \\
& \mathrm{D} i_{t}=\sqrt{ }\left[\left(x_{t-2}-x_{t+2}\right)^{2}+\left(y_{t-2}-y_{t+2}\right)^{2}\right]
\end{aligned}
$$

where $x$ and $y$ correspond with the projected coordinates $(\mathrm{m})$ of longitude and latitude respectively.

By looking at actual speed, as well as sudden changes in speed and sinuosity, we were able to identify the following behavioural categories on each track (as in, e.g. Grémillet et al. 2004): (1) Out-flight: from the start of the track (departure from the colony) until the sinuosity of the track was $>3.3$. This section is characterized by high flight speeds (usually $>40 \mathrm{~km} \mathrm{~h}^{-1}$ ). (2) Returnflight: section of the track from last hunting activity back to the colony, characteristics similar to (1) and it is identified in a similar way by the algorithm (traversing the track in reverse order). (3) Diving: section of the track characterized by a sudden drop in speed, from $>20 \mathrm{~km} \mathrm{~h}^{-1}$ to values close to 0 (dives). (4) Drifting on sea surface: characterized by speeds $<10 \mathrm{~km} \mathrm{~h}^{-1}$. This includes overnight sections, when gannets sleep on the water surface and drift along with ocean current and prevailing winds. (5) Hunting (search flight): the remaining sections of the track, characterized by medium flight speeds (between 20 to $40 \mathrm{~km} \mathrm{~h}^{-1}$ ) and higher values of sinuosity than out- or return-flights. This section possibly includes commuting between feeding grounds, with parts of directional flight, but we consider this as searching for new prey patches.

The time budget during foraging trips was described as: commuting (out- and return-flight) + hunting + drifting on the sea surface $=$ trip duration. Time budgets were analysed in hours and in fractions (of time between injection of DLW and final blood sample). Cape gannets are visual hunters that do not forage at night (for detailed time budgets during foraging trips, see Ropert-Coudert et al. 2004a). Gannets from both colonies were inactive for at least $9 \mathrm{~h}$ per night. For the analyses of behaviour, we were only interested in the active phase, so we subtracted $9 \mathrm{~h}$ for each night that was included in the foraging trips (daytime trip duration). The GPS tracks were collected within 2 mo at each island, too short for these activity patterns to be influenced by seasonal changes in the light-dark cycle (visual inspection GPS data). In total we obtained GPS data from 147 birds of known sex (Malgas: 34 in 200506, 55 in 2006-07; Ichaboe: 58 in 2005-06).

Hourly weather parameters (wind speed, wind direction and ambient temperatures) were available for each colony. For each foraging trip we calculated the average of the weather variables during the hours of the foraging trip. Weather data for Langebaan (Malgas Island) were obtained from the South African Weather Service, and for Stony Point (Ichaboe Island) from the Namibian Ministry of Fisheries and Marine Resources.
Doubly labelled water method. In each year we injected doubly labelled water (DLW) into breeding Cape gannets equipped with GPS loggers $(0.5 \mathrm{ml}$ DLW per kg of bird, subcutaneously). We used 2 DLW mixtures with different enrichments of the 2 isotopes: (1) 39.58 atom- $\%{ }^{2} \mathrm{H}$ and 58.54 atom- $\%{ }^{18} \mathrm{O}_{\text {; }}$ (2) 34.32 atom- $\%{ }^{2} \mathrm{H}$ and 63.76 atom- $\%{ }^{18} \mathrm{O}$. Immediately after injection, the birds were released near the colony. To estimate initial enrichment of the isotopes in the body, we kept 7 gannets individually in a box at Malgas and took a blood sample from a brachial vein $\sim 1 \mathrm{~h}$ after injection. These birds were then released near the colony and they left the colony within $10 \mathrm{~min}$. Gannets were captured when they came back from their foraging trip, the logger was removed, the bird was weighed, and the final blood sample was taken. Six duplicates of each blood sample were conserved in flame-sealed capillaries. An additional 12 birds (4 per year and per island) were bled to determine the natural background levels of the heavy isotopes.

The application of DLW was done with the utmost care: by the same 2 people (R.H.E.M. and R.A.N.) and in the same way. For equilibrium $1 \mathrm{~h}$ was enough as both isotopes did not change significantly between 67 and 85 min after injection (Deuterium $\mathrm{r}^{2}=0.037, B=$ 12.4; Oxygen-18 $\mathrm{r}^{2}=0.044, B=1.6$ ). The gannets we used to determine the initial enrichments were all from Malgas, as we assume that enrichment is similar in gannets from Ichaboe.

All isotope analyses were conducted at the Centre for Isotope Research (University of Groningen) following standard procedures (Gehre et al. 2004). The energy equivalence of $\mathrm{CO}_{2}$ we used was $27.33 \mathrm{~kJ} \mathrm{l}^{-1}$ $\mathrm{CO}_{2}$ (Gessaman \& Nagy 1988) and energy turnover rates calculated according to Speakman (1997). The average initial enrichments of the isotopes of 7 gannets were $1884 \%$ o $( \pm 126.8)$ for $\delta^{2} \mathrm{H}$ and $237 \%$ o $( \pm 17.7)$ for $\delta^{18} \mathrm{O}$. We injected a constant volume of DLW per $\mathrm{kg}$ body mass and could thus average these initials for all gannets. We scaled the initial values for each bird of which we did not take an initial sample according to the amount of DLW injected and their body mass. We acknowledge some uncertainties in this procedure, but the single sample method does allow reliable estimates of energy expenditure (Speakman 1997). The advantage of this method is the lower stress levels subjected to the focal birds.

We injected 45 gannets (Malgas $\mathrm{n}=26$; Ichaboe $\mathrm{n}=$ 19), from which we collected 41 final blood samples. We rejected 14 samples after analyses: 5 samples had ${ }^{18} \mathrm{O}$ or ${ }^{2} \mathrm{H}$ concentrations too close to background values, in 7 samples the duplicate concentration measurements varied more than $5 \%$ for either one of the isotopes, and in 2 samples the difference between the initial and final sample was too small. From 27 birds we 
obtained an estimate of the energy expenditure during the trip (Malgas: 8 in 2005-06, 8 in 2006-07; Ichaboe: 11 in 2005-06). Because we measured energy expenditure only during foraging trips, it is strictly speaking not DEE. We will therefore denote the rate of energy expenditure during the trip as trip energy expenditure (TEE) in $\mathrm{kJ} \mathrm{d}^{-1}$.

The basal metabolic rate (BMR) of Cape gannets was determined by Adams et al. (1991) as $718 \mathrm{~kJ} \mathrm{~d}^{-1}$, but they used $25.8 \mathrm{~kJ} \mathrm{l}^{-1}$ as an energy equivalence of $\mathrm{CO}_{2}$. We recalculated BMR with $27.33 \mathrm{~kJ} \mathrm{l}^{-1}$ as energy equivalence, which yields a BMR of $761 \mathrm{~kJ} \mathrm{~d}^{-1}$.

Statistical analyses. Results are presented as mean \pm SD. We analysed trip duration, time budgets, and number of dives during the trip with respect to wind speed, wind direction, and ambient temperatures using General Linear Models (GLM; SPSS 14.0). None of the parameters was transformed. The residuals for all the final models presented were normally distributed. For all models we deleted non-significant explanatory variables backwards until the final model was obtained. The wind direction was in degrees from the north. Due to the prevailing southern winds, this parameter was normally distributed and needed no transformation. One bird made 349 dives (Dixon Q-test: $\mathrm{Q}=$ $0.385, \mathrm{n}=149$, outlier) and 2 birds foraged when the wind came from a northwest direction $\left(>300^{\circ}\right)$. We present the diving analyses without these 3 exceptions in order to better interpret the estimates during prevailing conditions. The statistical outcomes, however, were the same for the models with these outliers. All models that explored the association between TEE and weather and foraging variables were built up in the same way: island, year, and time of day (morning or afternoon) were included as factors, and body mass and the weather parameters (temperature, wind speed, and wind direction) as covariates. As behavioural variables we included fractions flying (commuting + hunting) or hunting, flight speed and diving rate (dives per hour hunting). Time in the colony was also included in the analyses. We present the model with the highest $\mathrm{r}^{2}$ (either the model with fraction flying or fraction hunting).

\section{RESULTS}

\section{Weather conditions at the colonies}

At-sea weather data were not available. The data we applied to the birds were collected on land, and we assumed that they were associated with the conditions at sea.

The wind conditions differed significantly between the 2 breeding colonies. Gannets from Malgas Island had to forage in weaker winds than the birds from Ichaboe $\left(17.6 \mathrm{~km} \mathrm{~h}^{-1}, \mathrm{n}=89 ; 29.2 \mathrm{~km} \mathrm{~h}^{-1}, \mathrm{n}=55\right.$ respectively, 1 -way ANOVA: $F_{1,143}=89.0, \mathrm{p}<0.001$ ). Around Ichaboe, the winds also showed more variation in strength than around Malgas (SD: Malgas 5.2; Ichaboe 9.6). The wind direction also differed slightly between the islands: the winds around Malgas came from south-southwest (194 ${ }^{\circ}$ from north), whereas around Ichaboe the winds came from southwest $\left(223^{\circ}\right.$ from north, 1-way ANOVA: $\left.F_{1,143}=34.2, \mathrm{p}<0.001\right)$. The average temperature during foraging trips was the same on both islands (mean $18.3^{\circ} \mathrm{C} \pm 2.1,1$-way ANOVA: $F_{1,143}=1.5, \mathrm{p}=0.225$ ).

\section{Foraging behaviour}

Table 1 gives an overview of the average behaviours and time budgets of the Cape gannets per sex and per island during our study.

We first investigated which variables were associated with daytime trip duration (total trip duration minus night hours). In 2005-06, the average daytime trip duration did not differ between Malgas and Ichaboe $(18.0 \pm 8.4 \mathrm{~h}, \mathrm{n}=34$ and $17.1 \mathrm{~h} \pm 7.7, \mathrm{n}=58$ respectively). Trips on Malgas were $2.8 \mathrm{~h}$ longer in 2005-06 than in 2006-07. Foraging trips of female gannets $(18.0 \pm 7.6, \mathrm{n}=74)$ were on average $3.2 \mathrm{~h}$ longer than thoses of males $(14.8 \pm 7.0, n=73)$. These sex differences were most pronounced at Malgas in 2005-06 (Fig. 1). Heavier gannets made shorter trips than lighter birds, but wing size was not associated with daytime trip duration. Foraging trip duration was not

Table 1. Morus capensis. Foraging parameters (mean $\pm \mathrm{SD}$ ) per sex and per island. Time budgets are during foraging trips. Malgas: data from 2005-06 and 2006-07; Ichaboe: data from 2005-06. n = sample size

\begin{tabular}{|c|c|c|c|c|c|c|c|c|c|}
\hline \multirow{2}{*}{ Island } & \multirow[t]{2}{*}{ Sex } & \multirow[t]{2}{*}{$\mathrm{n}$} & \multirow{2}{*}{ Mass (g) } & \multirow{2}{*}{$\begin{array}{l}\text { Daytime trip } \\
\text { duration (h) }\end{array}$} & \multirow{2}{*}{$\begin{array}{c}\text { Distance } \\
\text { covered }(\mathrm{km})\end{array}$} & \multirow{2}{*}{$\begin{array}{l}\text { Number } \\
\text { of dives }\end{array}$} & \multirow[b]{2}{*}{ Commuting } & \multirow{2}{*}{$\begin{array}{l}\text { - Fraction } \\
\text { Hunting }\end{array}$} & \multirow[b]{2}{*}{ Drifting } \\
\hline & & & & & & & & & \\
\hline \multirow[t]{2}{*}{ Malgas } & female & 42 & $2692 \pm 223$ & $17.9 \pm 7.7$ & $447 \pm 230$ & $82.4 \pm 41.6$ & $0.105 \pm 0.076$ & $0.297 \pm 0.097$ & $0.599 \pm 0.108$ \\
\hline & male & 46 & $2584 \pm 197$ & $13.8 \pm 5.9$ & $365 \pm 175$ & $67.6 \pm 39.0$ & $0.115 \pm 0.117$ & $0.351 \pm 0.110$ & $0.535 \pm 0.139$ \\
\hline \multirow[t]{2}{*}{ Ichaboe } & female & 31 & $2475 \pm 127$ & $18.3 \pm 7.6$ & $496 \pm 210$ & $39.5 \pm 19.7$ & $0.100 \pm 0.072$ & $0.502 \pm 0.127$ & $0.398 \pm 0.109$ \\
\hline & male & 25 & $2379 \pm 111$ & $15.8 \pm 8.0$ & $402 \pm 164$ & $46.5 \pm 35.4$ & $0.117 \pm 0.087$ & $0.497 \pm 0.107$ & $0.385 \pm 0.132$ \\
\hline
\end{tabular}




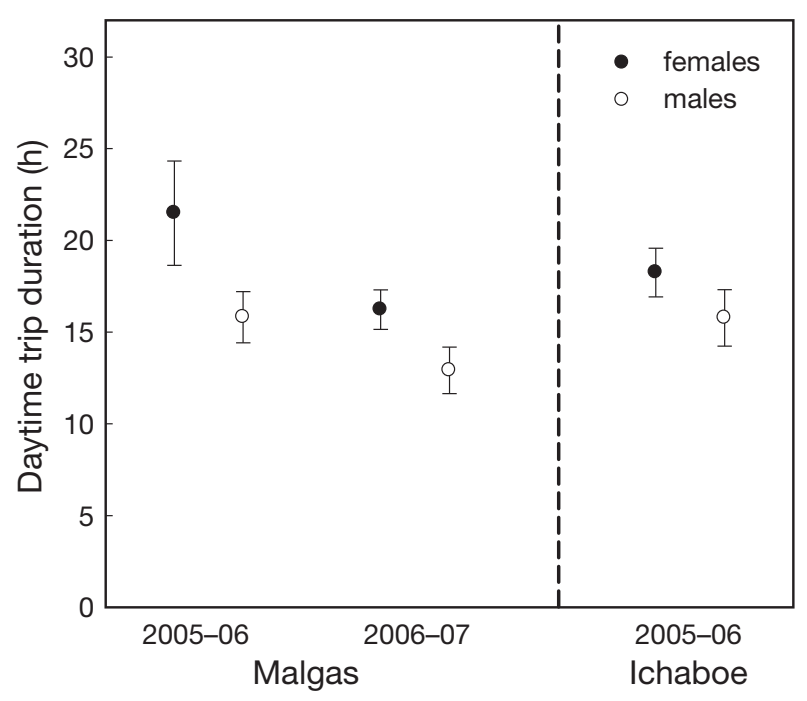

Fig. 1. Morus capensis. Daytime trip duration (mean $\pm 1 \mathrm{SE}$ ) per sex. Data from Malgas Island (left panel) and Ichaboe Island (right panel) during 2 years. Averages are calculated from a total of 147 GPS tracks of foraging trips

associated with any of the weather parameters. In the final model, sex and body mass explained $9.1 \%$ of the variation in daytime trip duration (GLM: $\operatorname{sex} B=3.9$, $\mathrm{SE}=1.2, F_{1,139}=10.2, \mathrm{p}=0.002$; body mass $B=-7.3$, $\left.\mathrm{SE}=3.0, F_{1,139}=6.1, \mathrm{p}=0.015\right)$. No significant interactions were found. The total distance flown during foraging trips was strongly and positively correlated with daytime trip duration $(\mathrm{r}=0.867, \mathrm{p}<0.001)$.

The time allocation during foraging trips (expressed in hours commuting, hunting or drifting on the sea surface) did not differ between the sexes or years and was not associated with any of the weather variables. The hours commuting were not associated with the daytime trip duration and did not differ between the islands (Fig. 2a, Table 2). Both the hours spent hunting and the hours spent drifting at the sea surface were positively associated with daytime trip duration (Fig. 2b,c, Table 2). At Ichaboe Island the gannets spent more time hunting than at Malgas, whereas at Malgas they spent more of their time drifting on the sea surface (Fig. 2b,c). Furthermore, gannets that left earlier during the day spent more of their time drifting on the sea surface (Table 2). In none of the models the interaction between island and daytime trip duration contributed significantly to the explained variance. The fraction drifting on the sea surface (as fraction of daytime trip duration) increased with foraging trip duration, but faster so at Ichaboe. This was because during shorter trips Malgas birds spent a larger fraction of their time drifting on the sea surface, and this difference between the islands diminished during
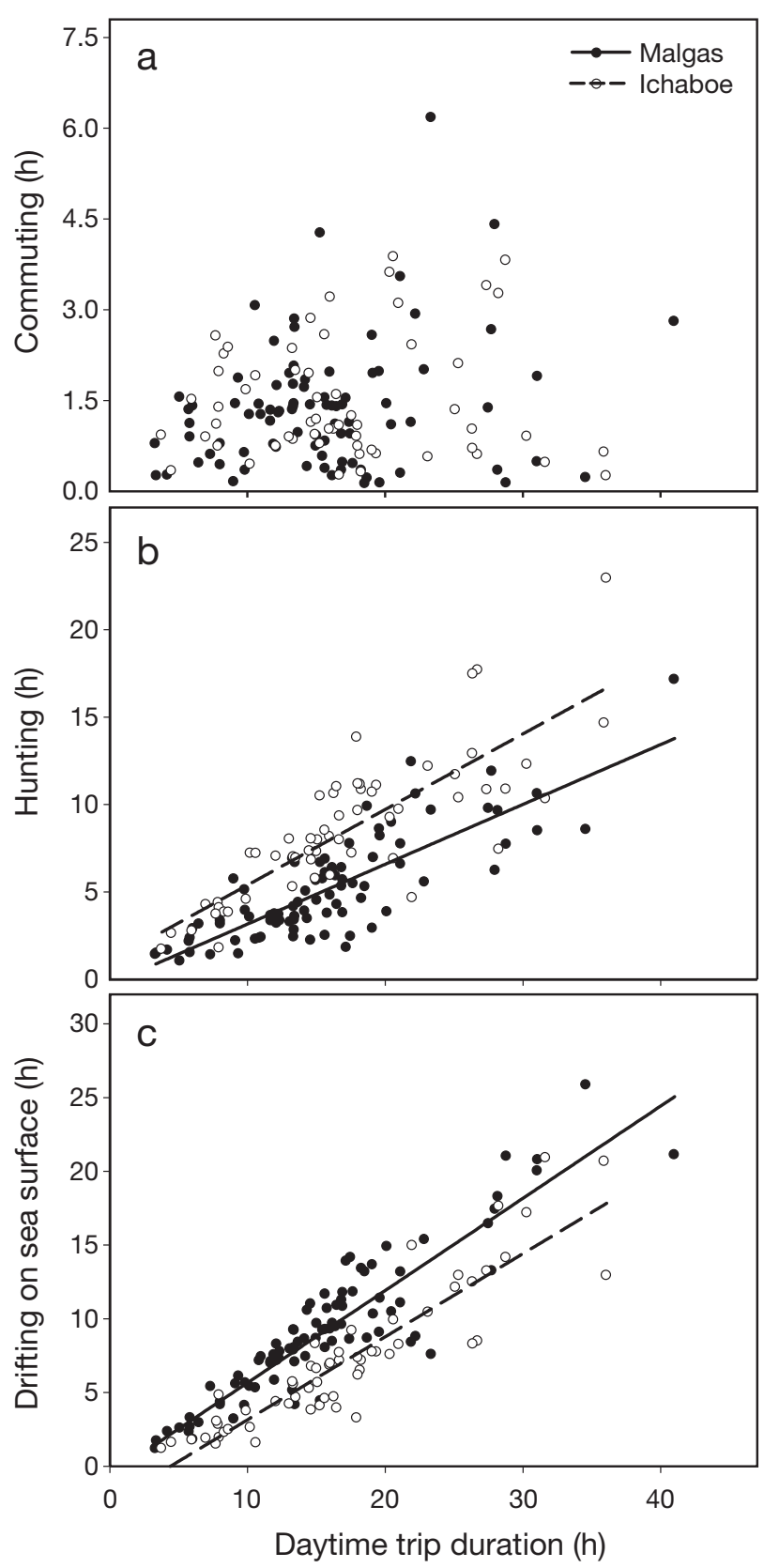

Fig. 2. Morus capensis. Time allocation from 2 colonies during foraging trips: (a) hours commuting, (b) hours hunting, and (c) hours drifting at the sea surface against daytime trip duration. Data are from a total of 147 GPS foraging tracks. $\bullet=$ data from Malgas Island during 2 years (2005-06 and 2006-07); $\mathrm{O}=$ data from Ichaboe Island in 2005-06

longer trips (island $\times$ fraction drifting $F_{1,136}=4.6, \mathrm{p}=$ 0.033).

Gannets from Malgas made about 30 dives more per foraging trip than Ichaboe birds (Malgas: $74.7 \pm 40.7$, $\mathrm{n}=88$; Ichaboe: $42.6 \pm 27.8, \mathrm{n}=56$; 1 -way ANOVA: $\left.F_{1,142}=26.8, \mathrm{p}<0.001\right)$. The number of dives tended to 
Table 2. Morus capensis. Results for a general linear model (GLM) with hours (a) commuting, (b) hunting, and (c) drifting during daytime foraging trips as dependent variables. The $\mathrm{r}^{2}$ is for each final model. Data are from 2 years (2005-06 and 200607 ) and 2 breeding colonies. Commuting $\mathrm{df}=1,137$; Hunting $\mathrm{df}=1,136 ;$ Drifting $\mathrm{df}=1,135$

\begin{tabular}{|c|c|c|c|}
\hline & $B(\mathrm{SE})$ & $F_{1,137}$ & $\mathrm{p}$ \\
\hline \multicolumn{4}{|l|}{ a. Commuting (h) } \\
\hline Intercept & $1.13(0.21)$ & 29.4 & $<0.001$ \\
\hline Daytime trip duration (h) & $0.02(0.01)$ & 1.9 & $\begin{array}{rl} & 0.169 \\
2 & 0.070\end{array}$ \\
\hline \multicolumn{4}{|c|}{$\begin{array}{l}\text { Rejected variables: } \\
\text { Island, Year, Sex, Time of day, Body mass, Wind speed } \& \\
\text { direction, Temperature }\end{array}$} \\
\hline \multicolumn{4}{|l|}{ b. Hunting (h) } \\
\hline Intercept & $1.96(0.49)$ & 1.4 & 0.242 \\
\hline Island & & 69.8 & $<0.001$ \\
\hline Malgas & $-2.93(0.35)$ & & \\
\hline Daytime trip duration (h) & $0.39(0.02)$ & 274.4 & $\begin{aligned}< & <0.001 \\
& =0.733\end{aligned}$ \\
\hline \multicolumn{4}{|c|}{ Rejected variables: } \\
\hline \multicolumn{4}{|c|}{$\begin{array}{l}\text { Year, Sex, Time of day, Body mass, Wind speed \& direction, } \\
\text { Temperature }\end{array}$} \\
\hline \multicolumn{4}{|l|}{ c. Drifting (h) } \\
\hline Intercept & $-3.35(0.49)$ & 12.9 & $<0.001$ \\
\hline Island & & 73.5 & $<0.001$ \\
\hline Malgas & $2.97(0.35)$ & & \\
\hline Time of day & & 4.1 & 0.044 \\
\hline Morning & $0.69(0.34)$ & & \\
\hline Daytime trip duration (h) & $0.59(0.02)$ & 635.1 & $\begin{aligned}< & <0.001 \\
& =0.839\end{aligned}$ \\
\hline \multicolumn{4}{|c|}{ Rejected variables: } \\
\hline Year, Sex, Body mass, Winc & speed \& direct & ion, Tem & iperature \\
\hline
\end{tabular}

increase with stronger winds (Fig. 3a), but was not associated with temperature or wind direction and did not differ between the sexes or years (Table 3). Gannets made more dives during longer trips and this increase was stronger at Malgas than at Ichaboe (Table 3, Fig. 3b). The diving rate (dives per hour hunting) was constant between the islands with daytime trip duration, but at Malgas, gannets had a higher diving rate (GLM: island $F_{1,134}=82.9, \mathrm{p}<0.001$; trip duration $\mathrm{ns}$; island $\times$ trip duration $\mathrm{ns}$ ). The diving rate decreased $t$ both island when more time was spent hunting, but at a faster rate at Malgas than at Ichaboe (interaction: island $\times$ hunting $F_{1,132}=7.7, \mathrm{p}=0.006$; Fig. 3c). This was due to the higher diving rate of Malgas gannets when little time was spent hunting.

Ground speed during flight could be accurately derived for all trips. At Malgas gannets flew on average $5 \mathrm{~km} \mathrm{~h}^{-1}$ faster than gannets from Ichaboe (48.1 \pm $6.1 \mathrm{~km} \mathrm{~h}^{-1} ; 43.1 \pm 4.6 \mathrm{~km} \mathrm{~h}^{-1}$, respectively, 1-way ANOVA $F_{1,145}=28.5, \mathrm{p}<0.001$ ). Flight speed did not differ between the sexes and was not associated with any of the wind parameters.
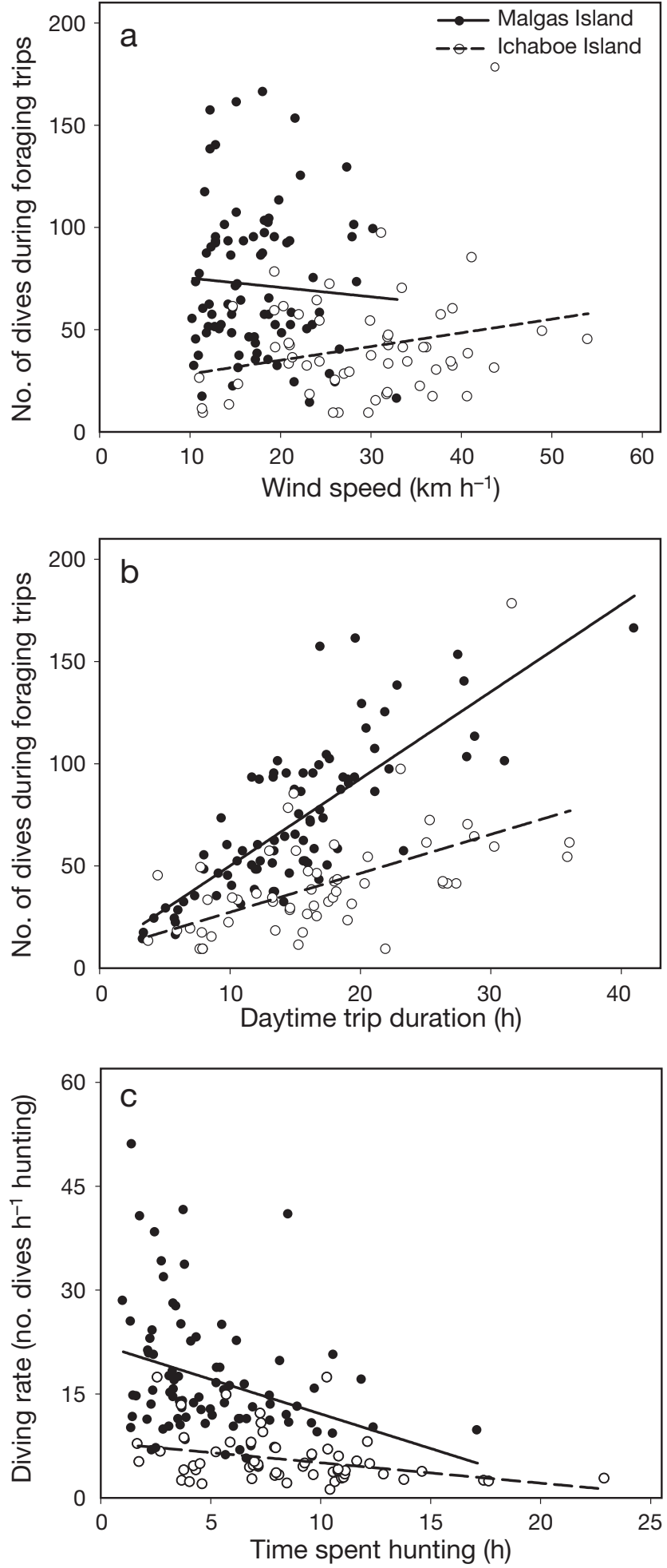

Fig. 3. Morus capensis. Number of dives plotted against (a) wind speed $\left(\mathrm{km} \mathrm{h}^{-1}\right)$, (b) daytime trip duration (h), and (c) diving rate (dives per hour foraging) plotted against time spent hunting during the foraging trip. Data are from a total of 147 GPS foraging tracks. = data from Malgas Island during 2 years (2005-06 and 2006-07); O = data from Ichaboe Island in 2005-06 
Table 3. Morus capensis. Results of a general linear model (GLM) with number of dives during foraging trips as dependent variable. Data are from 2 years (2005-06 and 2006-07) and from 2 breeding colonies

\begin{tabular}{|lrrr|}
\hline Number of dives & $B(\mathrm{SE})$ & $F_{1,130}$ & \multicolumn{1}{c|}{$\mathrm{p}$} \\
\hline Intercept & $-12.3(12.90)$ & 1.5 & 0.225 \\
Island & & 0.01 & 0.908 \\
$\quad$ Malgas & $1.3(11.25)$ & & \\
Wind speed $\left(\mathrm{km} \mathrm{h}^{-1}\right)$ & $0.61(0.31)$ & 3.8 & 0.053 \\
Daytime trip duration (h) & $2.08(0.44)$ & 139.1 & $<0.001$ \\
Island $\times$ Daytime trip & & 22.6 & $<0.001$ \\
$\quad$ duration (h) & & & \\
$\quad$ Malgas $\times$ Daytime trip & $2.78(0.58)$ & & \\
$\quad$ duration (h) & & & $\mathrm{r}^{2}=0.647$ \\
& & & \\
Rejected variables: & & & \\
Year, Sex, Time of day, Body mass, Wind direction, Tem- \\
perature, Hunting
\end{tabular}

Trip energy expenditure

From 27 Cape gannets we obtained reliable estimates of trip energy expenditure (TEE). They weighed $2507 \pm$ $190 \mathrm{~g}$ at time of injection, and the total body water pool was estimated to be $58.0 \%( \pm 0.76)$. In 2005-06, the Malgas birds $(2525 \pm 200 \mathrm{~g}, \mathrm{n}=8)$ were insignificantly heavier than those at Ichaboe $(2464 \pm 159 \mathrm{~g}, \mathrm{n}=11)$.

The average TEE was $4203 \pm 693 \mathrm{~kJ} \mathrm{~d}^{-1}$ for all 27 gannets together. In 2005-06, TEE did not differ between the colonies (1-way ANOVA $F_{1,19}=0.647, \mathrm{p}=$ 0.432), nor between the 2 breeding seasons at Malgas Island (1-way ANOVA $\left.F_{1,14}=0.621, p=0.444\right)$. TEE was insignificantly higher in females $(4306 \pm 914 \mathrm{~kJ}$ $\left.\mathrm{d}^{-1}\right)$ than in males $\left(4190 \pm 659 \mathrm{~kJ} \mathrm{~d}^{-1}\right)(1$-way ANOVA $\left.F_{1,20}=0.119, \mathrm{p}=0.733\right)$. In a GLM that included island, year, and body mass, TEE was not associated with any of these variables.
Sex was unknown in 5 individuals, and age of the chick of 2 gannets of which we measured TEE. We found no significant associations between TEE and sex or chick age and for further analyses we excluded sex and chick age.

\section{Flight costs}

TEE of Cape gannets was significantly and positively correlated with the distance flown $(r=0.430, p=0.025$, Fig. 4a) and tended to be associated with flight speed ( $r=0.378, p=0.052)$, but not with trip duration, hours flying, hours drifting and the number of dives. TEE was positively correlated with the fraction hunting $(\mathrm{r}=$ 0.386, $p=0.047$ ), not with the other fractions.

As a final step we made a full model to explore variation in TEE. TEE was higher at Malgas Island than at Ichaboe when controlled for wind speed and fraction flying, and did not differ between the 2 years (Table 4 ). Energy expenditure was not associated with departure time or body mass. TEE was also not associated with wind direction and ambient temperature, but increased with stronger winds (Fig. 4b). Gannets that flew a larger fraction of their foraging trips had increased TEE. TEE was not associated with the number of dives and flight speed in this model, nor the fraction of the time spent on the nest while injected with DLW. None of the interactions tested (island $\times$ wind speed, island $\times$ fraction flying and wind speed $\times$ fraction flying) were significant. The model explained $37.8 \%$ of the variation found in TEE (Table 4 ).

With this model we calculated the actual flight costs for different fractions flying during foraging trips. Average wind speed differed between the islands, so we used the average wind speed per island during the foraging trips of gannets we injected with DLW (Mal-
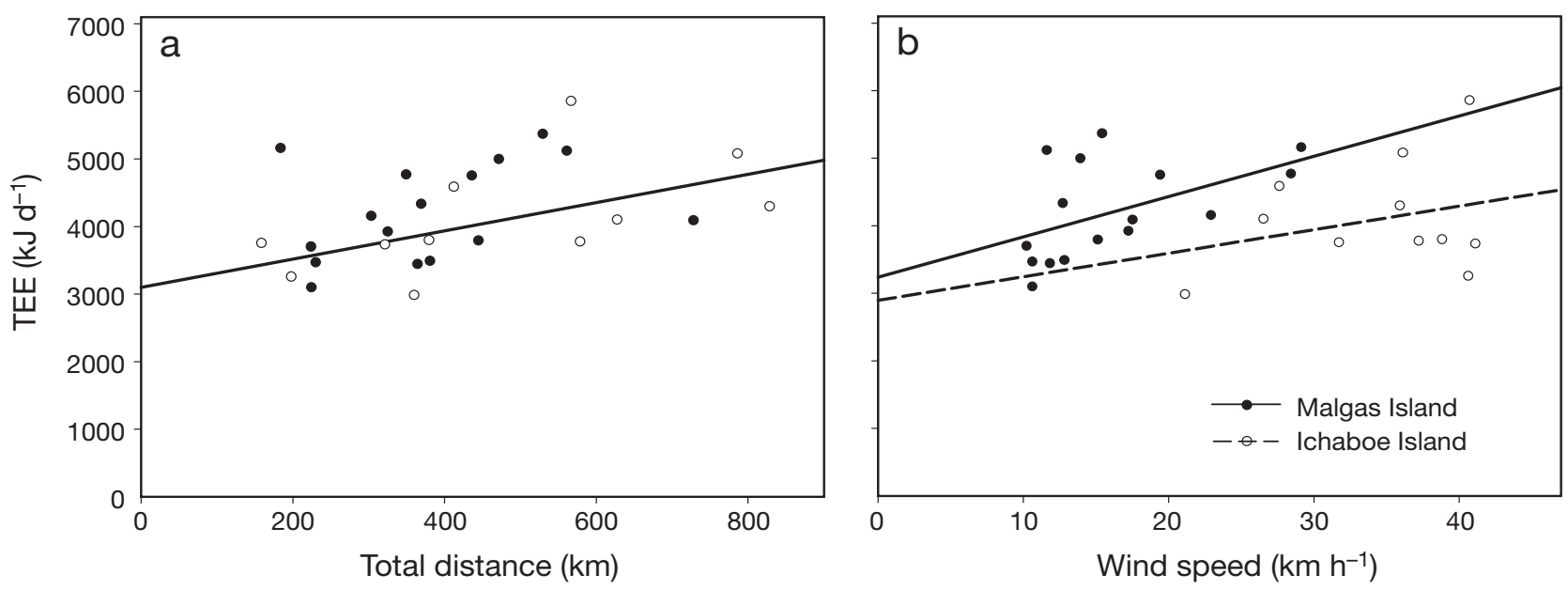

Fig. 4. Morus capensis. Trip energy expenditure (TEE) $\left(\mathrm{kJ} \mathrm{d}^{-1}\right)$ from 2 breeding colonies plotted against (a) total distance (km) covered during foraging trips (relationship significant overall but not per island), and (b) wind speed ( $\mathrm{km} \mathrm{h}^{-1}$ ). Malgas Island $(\bullet): \mathrm{n}=16$; Ichaboe Island (o): $\mathrm{n}=11$ 
Table 4. Morus capensis. Results for a general linear model with trip energy expenditure (TEE) as a dependent variable, and weather and behavioural parameters as potential explanatory parameters. $\mathrm{n}=27$. Data are from 2 years $(2005-06$ and 2006-07) and from 2 breeding colonies

\begin{tabular}{|lccr|}
\hline TEE $\left(\mathrm{kJ} \mathrm{d}^{-1}\right)$ & $B(\mathrm{SE})$ & $F_{1,23}$ & $\mathrm{p}$ \\
\hline Intercept & $829.4(911.2)$ & 4.9 & 0.037 \\
Island & & 10 & 0.004 \\
$\quad$ Malgas & $1488.6(470.5)$ & & \\
Wind speed $\left(\mathrm{km} \mathrm{h}^{-1}\right)$ & $56.5(20.1)$ & 7.9 & 0.010 \\
Fraction flying & $4310.6(1536.9)$ & 7.9 & 0.010 \\
& & $\mathrm{r}^{2}=0.378$ \\
Rejected variables: & & \\
Year, Body mass, Time of day, Wind direction, Temperature, \\
Time on nest, Flight speed, Diving rate \\
\hline
\end{tabular}

gas: $16.3 \mathrm{~km} \mathrm{~h}^{-1}$; Ichaboe: $34.4 \mathrm{~km} \mathrm{~h}^{-1}$ ). The regression lines per island are then:

$$
\begin{aligned}
& \mathrm{TEE}_{\text {Ichaboe }}=2773+(4311 \times \text { fraction flying }) \mathrm{kJ} \mathrm{d}^{-1} \\
& \mathrm{TEE}_{\text {Malgas }}=3239+(4311 \times \text { fraction flying }) \mathrm{kJ} \mathrm{d}^{-1}
\end{aligned}
$$

If gannets from both islands did not fly during the day, energy expenditure would be estimated to be $2773 \mathrm{~kJ}$ $\mathrm{d}^{-1}$ or $3.6 \times$ BMR $\left(761 \mathrm{~kJ} \mathrm{~d}^{-1}\right)$ at Ichaboe and $3239 \mathrm{~kJ} \mathrm{~d}^{-1}$ $(4.3 \times \mathrm{BMR})$ at Malgas. If gannets flew the whole day, energy expenditure would be $7084(9.3 \times \mathrm{BMR})$ at Ichaboe and about $7550(9.9 \times \mathrm{BMR})$ at Malgas. From these values we could estimate average flight costs as $7317 \mathrm{~kJ} \mathrm{~d}^{-1}$ or $84.7 \mathrm{~W}$.

\section{DISCUSSION}

We explored variation in foraging behaviour and the associated energy expenditure of Cape gannets from 2 breeding colonies on 2 different islands. Foraging trip duration was the same for all gannets, but the birds from Malgas Island (South Africa) spent less time hunting, and made considerably more dives during their foraging trips than those from Ichaboe Island (Namibia). The average TEE was $4203 \mathrm{~kJ} \mathrm{~d}^{-1}$ ( 5.5× $\mathrm{BMR}$ ) and did not differ between the islands. Within islands, TEE increased with wind speed and the fraction flying during trips. Under the same wind conditions, flight costs were slightly higher at Malgas $(87.4 \mathrm{~W})$ than at Ichaboe $(82.0 \mathrm{~W})$. At Malgas, these foraging costs were associated with more dives during foraging trips in weaker winds compared to Ichaboe.

\section{Limitations of the study}

Both the behavioural data and the estimates on energy expenditure were based on several as- sumptions. Deriving behaviours from GPS dataloggers, i.e. changes in speed and sinuosity, is common practice in seabird studies (Grémillet et al. 2004, Lewis et al. 2006, Bailleul et al. 2007, Weimerskirch et al. 2007). We assume that the GPS positions and their time base are correct. With the ongoing development of these devices, estimates will inevitably become more reliable. Our estimates of Cape gannet dives are within the ranges of other studies using time-depth recorders (Grémillet et al. 2004, Ropert-Coudert et al. 2004a, Pichegru et al. 2007). Discussions with other researchers deploying the same devices and thorough inspections of the GPS tracks made us confident that our observations do reflect the actual patterns to a large extent. Nevertheless, our results should be interpreted and valued in the light of these assumptions and uncertainties.

\section{Foraging behaviour}

Cape gannets from Malgas made considerably more dives during foraging trips than birds from Ichaboe, during which perhaps fewer or smaller prey were caught. At Ichaboe, parents hunted more during their foraging trips, and probably with a higher success rate: chicks at Ichaboe were growing faster than at Malgas for 3 consecutive breeding seasons (Mullers 2009). Stronger winds were positively associated with the number of dives, possibly due to lower success rates per dive (Finney et al. 1999). This relation was only found at Ichaboe (Fig. 3a). Around Malgas, the gannets always needed a large number of dives, even under weaker winds. This all indicates that around Malgas, gannets needed more dives per trip, thus had a lower foraging efficiency, likely because food availability was lower than around Ichaboe.

Gannets from Malgas had faster mean travelling speeds than birds from Ichaboe, probably because they spent fewer hours in search flight, which is less directional and slower. It has also been suggested that gannets from Malgas use the prevailing southern winds to increase their flight speed on their homebound journey (Grémillet et al. 2004). Fig. 2 in Lewis et al. (2006) supports that gannets from Malgas use these winds more than birds from Ichaboe after foraging.

\section{Energy expenditure}

The TEE of Cape gannets amounted to $4203 \mathrm{~kJ} \mathrm{~d}^{-1}$. In the breeding season of 1981-82, Adams et al. (1991) found a positive relationship between DEE and time off nest $\left(\mathrm{CO}_{2} \mathrm{l} \mathrm{d}^{-1}=1.0 \times(\%\right.$ time off nest $\left.)+81\right)$. In our 
study, the gannets spent on average $85 \%$ of the time between injection with DLW and the final blood sample off the nest, due to some birds that arrived at the colony after our last nest check and spent a night on their nest. This fraction of the time spent on the nest was not associated with TEE. If we want to compare the TEE of gannets during our study with that of gannets measured by Adams et al. (1991), we should fill in $85 \%$ (time off nest) in their equation. The TEE would then be $6.0 \times$ BMR in 1981-82, almost similar to our results $(5.5 \times \mathrm{BMR})$.

To estimate DEE from TEE we need time budgets and energy expenditure when on the island from the Cape gannets. Bijleveld \& Mullers (2009) observed nest attendance of gannets from Ichaboe in 2005-06. These birds spent on average $43 \%$ of their time on the nest. Energy expenditure at the nest was estimated to be $2.9 \times$ BMR by Adams et al. (1991). DEE of Cape gannets in our study would then be estimated at $(0.43 \times$ $2.9)+(0.57 \times 5.5)=4.4 \times \mathrm{BMR}$. This value is close to the optimal working capacity of $4 \times$ BMR proposed by Drent \& Daan (1980). We do not know if gannets from Malgas had the same time budgets to extrapolate this estimate to those gannets as well.

It has been suggested that Cape gannets were working at their energetic limits (Lewis et al. 2006, Bijleveld \& Mullers 2009), and could only marginally increase their foraging effort if needed. During our study, TEE did not differ between gannets from the 2 breeding colonies. Gannets from Malgas also did not allocate more time to hunting, even while their chicks were growing poorly (Mullers 2009). This would suggest lower energetic flexibility during foraging trips. The gannets spent about the same amount of energy during foraging trips as in 1981-82 (Adams et al. 1991). In 1981-82, good quality prey was readily available for gannets from Malgas (Berruti et al. 1993), which would facilitate increased energy expenditure. The energetic gain during foraging trips for gannets in our study would be lower due to reduced availability of food (Crawford et al. 2007) and the lower quality of alternative prey (Pichegru et al. 2007). One explanation for the fact that time budgets, unlike energy expenditure, were different between the islands could be that Cape gannets at Malgas and Ichaboe were both foraging at their maximum energetic sustainable levels, likely due to a decrease in energy gain during foraging trips forcing the birds to the limits of their expenditure. An experimental study at Ichaboe in 2005-06 showed indeed that partners of handicapped birds could not fully compensate for the reduced parental care of their partner (Bijleveld \& Mullers 2009). Chicks of handicapped gannets grew slower and had lower survival rates, which was associated with parental body condition.

\section{Flight costs}

Sustained flapping flight and plunge-diving behaviour are associated with high at-sea metabolic rates of seabirds (Birt-Friesen et al. 1989, Shaffer et al. 2001, Jodice et al. 2003). At sea, DEE in northern gannets Morus bassanus, for example, was estimated to be $8.1 \times$ BMR (Birt-Friesen et al. 1989), in Cape gannets this was 6.5 times BMR (Adams et al. 1991). In our study, Cape gannet TEE was positively correlated with the fraction hunting during foraging trips, which incorporates increased flapping during search flights and plunge-diving. These findings are in accordance with energy expenditure of black-legged kittiwakes Rissa tridactyla (Jodice et al. 2003). Birt-Friesen et al. (1989) also measured flight costs in northern gannets, which allow a comparison with the flight costs of Cape gannets. The flight costs of Cape gannets were 82.0 W for gannets from Ichaboe and $87.4 \mathrm{~W}$ for Malgas gannets, after correction for wind speed, or an average of ca. 85 W. For northern gannets, DEE when only flying was $11.3 \times$ BMR (equation from Fig. 1 in Birt-Friesen et al. 1989), which accounts to flight costs of $97 \mathrm{~W}$. Northern gannets weigh on average $0.7 \mathrm{~kg}$ more, which may account for the difference with Cape gannets.

Several studies have evaluated the effect of wind speed on foraging costs. Wind speed either decreases flight costs for seabirds due to increased time spent soaring (Flint \& Nagy 1984, Ballance 1997) or birds become less active during periods of weak winds (Schreiber \& Chovan 1986, Jouventin \& Weimerskirch 1990, Furness \& Bryant 1996). In Cape gannets, stronger winds increased energy expenditure perhaps due to increased wing flapping (Alerstam et al. 1993, Weimerskirch et al. 2000) or decreased foraging success due to rippling of the sea surface (Finney et al. 1999). At Ichaboe, gannets needed more dives with stronger winds, indicating indeed a decreased foraging success under stronger winds, which increased flight costs. Although heart rate was not much higher during flapping flight compared to gliding (RopertCoudert et al. 2006), sustained periods of flapping flight during stronger winds would likely increase metabolic rates of foraging gannets. The winds around Malgas were possibly not strong enough for longer periods of gliding, increasing flight costs.

\section{CONCLUSION}

Cape gannets from Malgas and Ichaboe were possibly foraging at the boundaries of their sustainable energetic expenditure. The weaker winds around Malgas would make it harder for gannets to take off from the water after each dive and increase energy expen- 
diture (Furness \& Bryant 1996, Shaffer et al. 2001). Gannets here spent a larger fraction of their trip drifting on the sea surface, which not only allowed them to digest the food ingested during foraging (RopertCoudert et al. 2004b), but also to rest from the increased costs of sustained flapping flight and plungediving (Falk et al. 2002). Cape gannet chicks from Ichaboe had faster growth rates during 3 consecutive breeding seasons, were heavier at fledging in 2005-06 and had higher survival rates than chicks from Malgas (Mullers 2009). This suggests that food around Ichaboe was more abundant, of better quality, or at least more predictable than around Malgas (Keller \& van Noordwijk 1994, Suryan et al. 2002, Wanless et al. 2005). At Ichaboe, the more reliable food supply and the potential use of stronger winds during foraging (Jouventin \& Weimerskirch 1990, Gilchrist et al. 1998, Weimerskirch et al. 2000) made it possible that the young grew better than at Malgas although the parents had similar energetic costs. Currently, the Cape gannets breeding at the west coast of southern Africa may be at the boundaries of their energetic limits and if the food conditions remain the same or even deteriorate, Cape gannet populations could likely decline even further (Crawford et al. 2007).

Acknowledgements. We thank L. G. Underhill and the late G. H. Visser for inspiring this project, and A. Bijleveld, F. Hermanides, L. Pichegru and J. van der Woude for help in the field. B. Verstappen-Dumoulin did all the lab analyses for the DLW samples. SANParks in South Africa and the Namibian Ministry of Fisheries and Marine Resources (MFMR) gave us permission to work on the islands and provided transport to and from the islands. R.H.E.M. was supported by a grant from the Netherlands Foundation for the Advancement of Tropical Research (WOTRO) to H. Visser. R.A.N. acknowledges support from the National Research Foundation, Pretoria. This paper is a contribution to the project LMR/EAF/03/02 on top predators of the Benguela Current Large Marine Ecosystem (BCLME) Programme.

\section{LITERATURE CITED}

Adams NJ, Abrams RW, Siegfried WR, Nagy KA, Kaplan IR (1991) Energy expenditure and food consumption by breeding Cape gannets Morus capensis. Mar Ecol Prog Ser 70:1-9

Alerstam T, Gudmundsson GA, Larsson B (1993) Flight tracks and speeds of Antarctic and Atlantic seabirds: radar and optical measurements. Phil Trans R Soc B 340:55-67

Bailleul F, Charrassin JB, Monestiez P, Roquet F, Biuw M, Guinet C (2007) Successful foraging zones of southern elephant seals from the Kerguelen Islands in relation to oceanographic conditions. Phil Trans R Soc B 362: 2169-2181

Ballance LT, Pitman RL, Reilly SB (1997) Seabird community structure along a productivity gradient: importance of competition and energetic constraint. Ecology 78:1502-1518

Berruti A, Underhill LG, Shelton PA, Moloney C, Crawford RJM (1993) Seasonal and interannual variation in the diet of 2 colonies of the Cape Gannet (Morus capensis) between 1977-78 and 1989. Colon Waterbirds 16:158-175

Bijleveld AI, Mullers RHE (2009) Reproductive effort in biparental care: an experimental study in long-lived Cape gannets. Behav Ecol 20:736-744

Birt-Friesen VL, Montevecchi WA, Cairns DK, Macko SA (1989) Activity-specific metabolic rates of free-living northern gannets and other seabirds. Ecology 70:357-367

Crawford RJM, Dundee BL, Dyer BM, Klages NTW, Meyer MA, Upfold L (2007) Trends in numbers of Cape gannets (Morus capensis), 1956/1957-2005/2006, with a consideration of the influence of food and other factors. ICES J Mar Sci 64:169-177

Drent RH, Daan S (1980) The prudent parent: energetic adjustments in avian breeding. Ardea 68:225-252

Ellis HI, Gabrielsen GW (2002) Energetics of free-ranging seabirds. In: Schreiber EA, Burger J (eds) Biology of marine birds. CRC Press, Boca Raton, FL, p 359-408

Falk K, Benvenuti S, Dall'Antonia L, Gilchrist G, Kampp K (2002) Foraging behaviour of thick-billed murres breeding in different sectors of the North Water polynya: an intercolony comparison. Mar Ecol Prog Ser 231:293-302

$>$ Finney SK, Wanless S, Harris MP (1999) The effect of weather conditions on the feeding behaviour of a diving bird, the common guillemot Uria aalge. J Avian Biol 30:23-30

Flint EN, Nagy KA (1984) Flight energetics of free-living sooty terns. Auk 101:288-294

Fridolfsson AK, Ellegren H (1999) A simple and universal method for molecular sexing of non-ratite birds. J Avian Biol 30:116-121

> Furness RW, Bryant DM (1996) Effect of wind on field metabolic rates of breeding northern fulmars. Ecology 77 : $1181-1188$

Gehre M, Geilmann H, Richter J, Werner RA, Brand WA (2004) Continuous flow $\mathrm{H}-2 / \mathrm{H}-1$ and (18)O/O-16 analysis of water samples with dual inlet precision. Rapid Commun Mass Spectrom 18:2650-2660

Gessaman JA, Nagy KA (1988) Energy-metabolism: Errors in gas-exchange conversion factors. Physiol Zool 61:507-513

Gilchrist HG, Gaston AJ, Smith JNM (1998) Wind and prey nest sites as foraging constraints on an avian predator, the glaucous gull. Ecology 79:2403-2414

Grémillet D, Dell'Omo G, Ryan PG, Peters G, Ropert-Coudert Y, Weeks SJ (2004) Offshore diplomacy, or how seabirds mitigate intra-specific competition: a case study based on GPS tracking of Cape gannets from neighbouring colonies. Mar Ecol Prog Ser 268:265-279

> Hodum PJ, Weathers WW (2003) Energetics of nestling growth and parental effort in Antarctic fulmarine petrels. J Exp Biol 206:2125-2133

Jodice PGR, Roby DD, Suryan RM, Irons DB, Kaufman AM, Turco KR, Visser GH (2003) Variation in energy expenditure among black-legged kittiwakes: effects of activityspecific metabolic rates and activity budgets. Physiol Biochem Zool 76:375-388

Jouventin P, Weimerskirch H (1990) Satellite tracking of wandering albatrosses. Nature 343:746-748

Keller LF, van Noordwijk AJ (1994) Effects of local environmental conditions on nestling growth in the great tit Parus major. Ardea 82:349-362

> Lewis S, Grémillet D, Daunt F, Ryan PG, Crawford RJM, Wanless S (2006) Using behavioural and state variables to identify proximate causes of population change in a seabird. Oecologia 147:606-614

Mullers RHE (2009) The commuting parent: energetic constraints in a long distance forager, the Cape gannet. PhD thesis, University of Groningen 
Mullers RHE, Tinbergen JM (2009) Parental provisioning behaviour predicts survival of Cape gannet chicks under poor conditions. Ardea 97:89-98

Pichegru L, Ryan PG, van der Lingen CD, Coetzee JC, Ropert-Coudert Y, Grémillet D (2007) Foraging behaviour and energetics of Cape gannets Morus capensis feeding on live prey and fishery discards in the Benguela upwelling system. Mar Ecol Prog Ser 350:127-136

Ropert-Coudert Y, Grémillet D, Kato A, Ryan PG, Naito Y, Le Maho Y (2004a) A fine-scale time budget of Cape gannets provides insights into the foraging strategies of coastal seabirds. Anim Behav 67:985-992

Ropert-Coudert Y, Grémillet D, Ryan PG, Kato A, Naito Y, Le Maho Y (2004b) Between air and water: the plunge dive of the Cape gannet Morus capensis. Ibis 146:281-290

Ropert-Coudert Y, Wilson RP, Grémillet D, Kato A, Lewis S, Ryan PG (2006) Electrocardiogram recordings in freeranging gannets reveal minimum difference in heart rate during flapping versus gliding flight. Mar Ecol Prog Ser 328:275-284

Schreiber RW, Chovan JL (1986) Roosting by pelagic seabirds: energetic, populational, and social considerations. Condor 88:487-492

Shaffer SA, Costa DP, Weimerskirch H (2001) Behavioural factors affecting foraging effort on breeding wandering albatrosses. J Anim Ecol 70:864-874

Editorial responsibility: Michael Castellini,

Fairbanks, Alaska, USA
Shealer DA (2002) Foraging behaviour and food of seabirds. In: Schreiber EA, Burger J (eds) Biology of marine birds. CRC Press, Boca Raton, FL, p 137-178

Snyder JP (1982) Map projections used by the U.S. Geological Survey. U.S. Geological Survey Bulletin 1532

Speakman JR (1997) Doubly Labelled Water: theory and practice. Chapman \& Hall, London

Suryan RM, Irons DB, Kaufman M, Benson J, Jodice PGR, Roby DD, Brown ED (2002) Short-term fluctuations in forage fish availability and the effect on prey selection and brood-rearing in the black-legged kittiwake Rissa tridactyla. Mar Ecol Prog Ser 236:273-287

Tieleman BI, Williams JB (2000) The adjustment of avian metabolic rates and water fluxes to desert environments. Physiol Biochem Zool 73:461-479

> Wanless S, Harris MP, Redman P, Speakman JR (2005) Low energy values of fish as a probable cause of a major seabird breeding failure in the North Sea. Mar Ecol Prog Ser 294:1-8

> Weimerskirch H, Guionnet T, Martin J, Shaffer SA, Costa DP (2000) Fast and fuel efficient? Optimal use of wind by flying albatrosses. Proc R Soc Lond B Biol Sci 267:1869-1874

> Weimerskirch H, Pinaud D, Pawlowski F, Bost CA (2007) Does prey capture induce area-restricted search? A fine-scale study using GPS in a marine predator, the wandering albatross. Am Nat 170:734-743

Submitted: April 18, 2009; Accepted: July 29, 2009

Proofs received from author(s): October 13, 2009 